\title{
Immunomodulatory Function of Vitamin D and Its Role in Autoimmune Thyroid Disease
}

\author{
Rui Zhao ${ }^{1}$, Wei Zhang ${ }^{1}$, Chenghong Ma ${ }^{1}$, Yaping Zhao ${ }^{1}$, Rong Xiong ${ }^{1}$, Hanmin Wang ${ }^{1}$, \\ Weiwen Chen ${ }^{1 *}$ and Song Guo Zheng ${ }^{2 *}$ \\ ${ }^{1}$ Department of Endocrinology, Qujing Affiliated Hospital of Kunming Medical University, Kunming, China, ${ }^{2}$ Division of \\ Immunology and Rheumatology, Ohio State University Wexner Medical Center and College of Medicine, Columbus, $\mathrm{OH}$, \\ United States
}

Vitamin $\mathrm{D}$ is one of the most important nutrients required by the human body. It is a steroid hormone that plays an important role in regulating calcium and phosphorus metabolism, and bone health. Epidemiological studies have revealed a close correlation between vitamin $\mathrm{D}$ and many common chronic diseases. Additionally, vitamin $\mathrm{D}$ has recently been shown to act as an immunomodulatory hormone, and, accordingly, vitamin $D$ deficiency was uncovered as a risk factor for autoimmune thyroid diseases, although the underlying mechanisms are still unknown. It is therefore necessary to disclose the role and mechanism of action of vitamin $D$ in the occurrence and development of autoimmune thyroid diseases. This knowledge will help design intervention and early treatment strategies for patients with autoimmune thyroid diseases who present with low levels of vitamin $\mathrm{D}$.

Keywords: vitamin D, immunomodulatory function, autoimmune thyroid disease, Hashimoto autoimmune thyroiditis, Grave's disease

\section{INTRODUCTION}

Vitamin D plays an important role in maintaining calcium and phosphorus balance, as well as bone health (1). Osteoporosis is a common manifestation of diseases affecting bone health due to an imbalance between osteoclast and osteoblast functions $(2,3)$. Vitamin D also plays an important part in many non-skeletal diseases $(4,5)$. Due to its roles in diabetes, cancer, autoimmunity, inflammatory responses, as well as muscle and cardiovascular disorders, it has gained increasing interest $(6,7)$. Such as Bouchemal et al. have mentioned the important role vitamin D plays in metabolic syndrome (8). Djeraba et al. have shown vitamin D deficiency was associated with active Behcet's disease (BD) and after the treatment of vitamin D down-modulates nitric oxide production in $\mathrm{BD}(9)$. We also previously reported that vitamin $\mathrm{D}$ deficiency is also a risk factor for neuropsychiatric disorders and autoimmune diseases (6). In addition, vitamin D, as it also appears to regulate the immune system, is a newly identified immunomodulatory hormone $(10,11)$. Among some common thyroid diseases, such as Hashimoto's thyroiditis (HT) and Graves' disease (GD), there are often autoimmune factors involved in their development (12). Current studies have found that the vitamin D receptor (VDR) is expressed on immune cells, where it can regulate their proliferation and differentiation, resulting in thyroid damage, and vitamin $\mathrm{D}$ has been shown to be associated with thyroid disease $(13,14)$. The underlying mechanisms, however, are not yet clear. We here aim to summarize the immunomodulatory effects of vitamin D in autoimmune thyroid 
disease (AITD) to understand how vitamin D exerts its immunomodulatory role in the body, and its influences and mechanisms in AITD.

\section{IMMUNOMODULATORY MECHANISMS OF VITAMIN D}

\section{Vitamin D Receptor}

Vitamin D receptor (VDR) is an important signaling molecule for mediating downstream biological effects of active vitamin $\mathrm{D}$. In the context of vitamin D-binding protein-dependent transport, $1,25(\mathrm{OH}) 2 \mathrm{D} 3$ binds to VDR on cells of the target organ to form a heterodimeric complex. There, the 1,25(OH)2D3-VDRRXR complex exerts its biological function through the following mechanism: it specifically binds to the promoter regions of target genes on the DNA, thus regulating transcriptional activity of these target genes (15). Previous research has shown that dendritic cells, macrophages, $\mathrm{T}$ cells, $\mathrm{B}$ cells, and other immune cells express VDR (16). Hence, vitamin D can affect immune cells by binding to VDR, and immune cells can also metabolize $1,25(\mathrm{OH}) 2 \mathrm{D} 3$, which is the active form of vitamin $\mathrm{D}$. In accordance with this, abnormal immune cells and inflammatory cytokines impact bone health $(17,18)$. Therefore, vitamin D has a regulatory effect on the body's innate and adaptive immune mechanisms.

\section{Effect of Vitamin D on Monocytes/Macrophages}

The change of vitamin D nutritional status has a great influence on innate immunity mediated by monocytes in response to infection. Vitamin D may be involved in inducing autophagy, and its deficiency may be responsible for impaired antimicrobial activity of monocytes. Studies have found that macrophages isolated from mice that had been fed a diet deficient in vitamin $\mathrm{D}$ featured impaired phagocytosis, reduced chemotaxis, decreased abilities to release anti-inflammatory cytokines and respond to inflammatory stimuli, and reduced tumor-killing activity. In addition, mice deficient in vitamin $\mathrm{D}$ showed low expression of macrophage-specific antigen, but it could be rescued by supplementation with active vitamin D (13). This study confirmed that vitamin $\mathrm{D}$ is a key factor in macrophage maturation. Moreover, vitamin D could promote differentiation of monocytes to macrophages, enhance both phagocytosis and chemotaxis, and increase anti-tumor activities of mononuclear macrophages. Toll-like receptors (TLRs) can identify pathogenassociated molecular patterns, and consequently induce immune responses. Vitamin D can inhibit the expression of TLR2 and TLR4 on the surface of monocytes, resulting in a state of insufficient immune responsiveness and reduced production of inflammatory cytokines, such as TNF- $\alpha$, and prevent overactivation of TLRs to inhibit inflammation (19). Indeed, TNF- $\alpha$ plays an important role during inflammation, and antiTNF- $\alpha$ antibody has a therapeutic benefit in humans suffering from the diseases stated above (20-24).

\section{Effects of Vitamin D on Antigen-Presenting Cells (APCs)}

APCs constitute a class of cells that can process antigens and present them to $\mathrm{T}$ cells, while being bound to major histocompatibility complex (MHC) molecules (25). Dendritic cells (DCs) represent the most powerful APC type. DCs can induce both innate and adaptive immune responses, and balance immune tolerance with immune activation $(26,27)$. Some studies have described the effects of $1,25(\mathrm{OH}) 2 \mathrm{D} 3$ on the morphology and function of DCs. Vitamin D can regulate the secretion of interleukins (ILs) by inhibiting the activation of p38 mitogenactivated protein kinase (MAPK) and nuclear factor-kB (NF$\mathrm{kB}$ ) signaling pathways in DCs. Then, vitamin D increases the production of anti-inflammatory cytokines, such as IL-10, and T-cell inhibitory molecules (programmed death-1, PD-1), and inhibits the secretion of pro-inflammatory cytokines IL-12, IL23 , TNF- $\alpha$, and IFN- $\gamma$, which are involved in the differentiation of helper $\mathrm{T}$ (Th)1 and Th17 cells (28-31). In addition, DCderived stimulatory signals are essential factors for activation of naïve $\mathrm{T}$ cells. Vitamin $\mathrm{D}$ can inhibit the maturation and differentiation of DCs, thus down-regulating the expression of the co-stimulatory molecules CD40, CD80, and CD86, as well as $\mathrm{MHC}$ class II molecules. Due to the lack of the mature DC surface molecules necessary, antigen-specific $\mathrm{T}$ cells are less responsive, or not at all (32). In line with this, $1,25(\mathrm{OH}) 2 \mathrm{D} 3$ inhibits the maturation of DCs, leading to reduced antigen uptake and activation of naïve $\mathrm{T}$ cells, which is an important process for suppressing autoimmunity.

\section{Effects of Vitamin D on T and B Cells}

It has been previously reported (33) that naive and memory $\mathrm{T}$ cells express VDR, which indicates that vitamin $\mathrm{D}$ can act directly on $\mathrm{T}$ cells and regulate $\mathrm{T}$ cell responses. Moreover, vitamin $\mathrm{D}$ can affect the distribution of Th1, Th2, and Th17 cells, consequently altering the functional subclasses of $\mathrm{T}$ cells. At present, studies have provided evidence that vitamin $\mathrm{D}$ can inhibit the conversion of antigen- and lectin-stimulated naïve CD4+ $\mathrm{T}$ cells to Th1 cells, and that vitamin $\mathrm{D}$ can also inhibit the production of IL- 2 and IFN- $\gamma$ by Th1 cells, decrease the secretion of IgG by B lymphocytes, and at the same time promote the transformation of Th1 to Th2 cells, and up-regulate the activity of the latter. Vitamin D promotes secretion of IL-4, IL-5, and IL-10 from Th2 cells, regulates Th1/Th2 cell ratios, and limits potential tissue damage caused by Th1-induced immune responses (34). Th17 cells constitute a newly identified subset of $\mathrm{T}$ cells (35). They have a pro-inflammatory effect in many inflammatory diseases (36-38), as they can secrete many cytokines, such as IL-17A, IL-17F, IL-21, IL-22, and IL-6, and bind CC-type chemokine 6 (CCL- 6 ) and TNF- $\alpha$. They participate in autoimmune disease processes and perform specific functions. IL-17 and IL-22 receptors are widely distributed, and play a synergistic and pro-inflammatory role, which may be the basis for inducing tissue inflammation and autoimmunity in Th17 activation. We and others provided evidence that vitamin D can inhibit both the differentiation of CD4+ T cells to Th17 cells and the secretion of IL-17 from Th17 cells $(11,39)$. Vitamin 
$\mathrm{D}$ also promotes the differentiation of naive CD4+ $\mathrm{T}$ cells to regulatory $\mathrm{T}$ cells (Treg). Unlike other effector $\mathrm{T}$ cells, Treg cells can regulate the body's immune response by regulating cytokine secretion and $\mathrm{T}$ cell activation (40-42).Vitamin D can also directly affect the proliferation of Treg cells without inhibiting their function, and promote the secretion of IL-10 by Treg cells $(43,44)$. Therefore, vitamin $\mathrm{D}$ plays an important role in autoimmune diseases and hosts transplant rejection. The reduction of Th17 cells usually coincides with the increase of Treg cells. An important focus of improving the treatment of autoimmune diseases is to restore the Th17/Treg imbalance that occurs during chronic inflammation. Vitamin D can regulate the Th17/Treg imbalance by up-regulating Treg cells and inhibiting Th17 cell differentiation (45).

$B$ cells also express VDR, but the effect of vitamin D on B cells is still controversial. One the one hand, vitamin $\mathrm{D}$ can induce low reactivity of $\mathrm{B}$ cells, or it can cause B cell apoptosis directly, inhibit the production of memory B cells, and reduce the production of immunoglobulins. One the other hand, 1,25(OH)2D3 may alter $\mathrm{CD} 4+\mathrm{T}$-cell responses, or suppress cytokine secretion by inhibiting the actions of monocytes/macrophages, thereby indirectly inhibit the functions of $\mathrm{B}$ cells (11). Indeed, the $\mathrm{B}$ cell response depends upon $\mathrm{T}$ cell help $(46,47)$. B cell surfaces also express enzymes involved in vitamin D metabolism, including 1- $\alpha$-hydroxylase and 24hydroxylase, indicating that vitamin $\mathrm{D}$ can affect the functions of B cells (33). Therefore, vitamin D has a potential role in diseases with B cell dysfunction. To sum up, vitamin D plays an important role in the occurrence and development of autoimmune diseases. Vitamin D can enhance innate immunity and regulate adaptive immune function.

\section{VITAMIN D DEFICIENCY AND HT}

HT, also known as Hashimoto's disease or chronic lymphocytic thyroiditis, is an AITD with unknown etiology. Current studies have shown that Th1/Th2 cell imbalance and Th1 cell activity enhancement are the main pathogenic factors of HT (48). Vitamin D may play an immunosuppressive role by inhibiting multiple parts of the HT immune response $(49,50)$, such as: (1) vitamin $\mathrm{D}$ binding to its receptor to prevent $\mathrm{DC}$-dependent $\mathrm{T}$ cell activation that then reduces the production of pro-inflammatory cytokines (IL-2, IL-5, IL-17, and TNF- $\alpha$ ), and decreasing the cytokine-mediated immune response; (2) vitamin D inhibiting autoimmune thyroiditis through down-regulating HLA class II gene expression in the thyroid, thus inhibiting lymphocyte proliferation and secretion of inflammatory cytokines; (3) vitamin $\mathrm{D}$ deficiency causing a large number of $\mathrm{B}$ cells to proliferate and differentiate into plasma cells, causing the latter to secrete large amounts of IgG, IgE, and other immunoglobulins, which eventually cause damage to thyroid cells and then trigger HT; and (4) vitamin D inhibiting differentiation of naïve T cells into Th17 cells, and suppressing the secretion of Th17-derived cytokines IL-17 and IL-21, while promoting the metabolism of Treg cells to restore the balance of the body's Th17/Treg cell ratio, and inhibit Th17 cell-induced thyroid inflammation (51).
A case-control study (52) found that each increase in serum 25(OH)D levels by $5 \mathrm{nmol} / \mathrm{L}$ reduced the risk of HT by 1.62 times. A study by Bozkurt et al. (53) showed that serum 25(OH)D levels in HT patients were significantly lower than those in the control group, and the severity of $25(\mathrm{OH}) \mathrm{D}$ deficiency was associated with the duration of HT and thyroid antibody levels. Others have demonstrated that serum $25(\mathrm{OH}) \mathrm{D}$ is negatively correlated with serum anti-TPO antibody in HT patients, which was found to be significantly reduced after 4 months of vitamin $\mathrm{D}$ supplementation in HT patients [daily oral administration of 1,200-4,000 IU vitamin D3, with the goal of $25(\mathrm{OH}) \mathrm{D}$ concentrations of up to $40 \mathrm{ng} / \mathrm{mL}$ ] (54). A large number of studies $(55,56)$ have also documented that vitamin $\mathrm{D}$ deficiency prevails in HT patients, that vitamin D is involved in the occurrence and development of HT, and that vitamin D supplementation helps to alleviate HT conditions. Botelho et al. examined 88 patients with HT and 71 euthyroid healthy subjects for vitamin D status and thyroid autoimmunity markers, as well as their relationship with cytokines produced by Th1, Th2, and Th17 cells. They found an association between vitamin D and TNF- $\alpha$, IL-5, and IL-17 levels in these patients, which indicated the relevance of this relationship with autoimmunity in HT (57). Nodehi et al. assessed the frequencies of Th1, Th17, Th2, and Treg cells and the levels of IFN- $\gamma$, IL-17, IL-4, and IL-10 in 34 HT patients, among which 17 patients were treated weekly with 50,000 IU of cholecalciferol and the rest were treated with placebo through oral administration for 3 months. They concluded that vitamin D supplementation provides beneficial immunological effects in HT patients through decreasing Th17/Treg cell ratio (58). However, controversial results have been reported (59). Zhang et al. concluded that vitamin D status was not associated with positive thyroid autoantibodies, but higher $25(\mathrm{OH}) \mathrm{D}$ levels were associated with lower TSH levels (60). Moreover, D'Aurizio et al. revealed that there was no differences in vitamin $\mathrm{D}$ deficiency and 25(OH)D levels between 100 AITD patients and healthy controls (61). Similarly, Yasmeh et al. reported that there was no positive correlation between vitamin D and TPOAb levels in HT males relative to the control group, thereby concluding that $\mathrm{HT}$ is not associated with higher rates of vitamin $\mathrm{D}$ deficiency relative to the control group (62). Therefore, more research data are still needed to verify the relationship between vitamin D deficiency and HT, which will help to determine whether vitamin D supplementation is effective for HT treatment.

\section{VITAMIN D DEFICIENCY AND GD}

GD, known as diffuse toxic goiter, is the most common cause of hyperthyroidism, and its pathogenesis is complex and unclear. Two groups have demonstrated $(63,64)$ that vitamin $\mathrm{D}$ inhibits the pathogenesis of GD through the following immunomodulatory mechanisms: (1) vitamin D inhibits the differentiation and maturation of DCs, decreases the secretion of the pro-inflammatory cytokines IL-2, IL-23, and IL-12 by DCs, and blocks hyperthyroidism caused by autoimmune responses; (2) vitamin D can directly act on Th1 and Th2 cells, and inhibit the occurrence of autoimmune responses by inhibiting 
Th1 cells, and by upregulating the activity of Th2 cells and the level of cytokines they secrete; and (3) vitamin D inhibits B cell proliferation, plasma cell differentiation, immunoglobulin secretion, and memory B cell production, and is associated with the onset of GD.

The aforementioned case-control study (52) also noted that each increase in serum $25(\mathrm{OH}) \mathrm{D}$ levels by $5 \mathrm{nmol} / \mathrm{L}$ reduced the risk of GD by 1.55 times. Zhang et al. (65) have shown that the lower the vitamin D level, the higher the serum thyrotrophin receptor antibody (TRAB) level in GD patients. These findings suggest that vitamin $\mathrm{D}$ deficiency may be one of the risk factors contributing to the onset of GD. Ahn et al. examined patients diagnosed with Graves' disease and treated with ATDs for more than 1 year after the discontinuation of ATD. This study have shown that low serum $25(\mathrm{OH}) \mathrm{D}$ levels are highly correlated with the incidence of GD recurrence, and that serum $25(\mathrm{OH}) \mathrm{D}$ may be an independent risk factor for predicting the recurrence of GD after the discontinuation of anti-thyroid drug (ATD) treatment (66). In this regard, opposing arguments have also been made. $\mathrm{Ke}$ et al. reported low serum vitamin D levels in HT patients, which did not alter significantly in GD patients compared with non-AITD controls (67). However, Cho et al. demonstrated that there was no beneficial effect of daily supplementation of vitamin $\mathrm{D}$ on the recurrence of Graves' disease within 1 year after the discontinuation of ATD. However, the time of recurrence was delayed in patients who reached sufficient levels of vitamin D after supplementation (68).

\section{CONCLUSIONS}

In recent years, there have been more and more studies on the action of vitamin $\mathrm{D}$ in non-skeletal diseases, especially on the regulatory effect of vitamin $\mathrm{D}$ on immune function. As a hormone of immune regulation, vitamin $\mathrm{D}$ has become a research focus. Current epidemiological statistics and clinical

\section{REFERENCES}

1. Bhattoa HP, Konstantynowicz J, Laszcz N, Wojcik M, Pludowski P. Vitamin D: Musculoskeletal health. Rev Endocr Metab Disord. (2017) 18:36371. doi: 10.1007/s11154-016-9404-x

2. Kong N, Lan Q, Su W, Chen M, Wang J, Yang Z, et al. Induced T regulatory cells suppress osteoclastogenesis and bone erosion in collageninduced arthritis better than natural T regulatory cells. Ann Rheum Dis. (2012) 71:1567-72. doi: 10.1136/annrheumdis-2011-201052

3. Luo Y, Wu W, Gu J, Zhang X, Dang J, Wang J, et al. Human gingival tissue-derived MSC suppress osteoclastogenesis and bone erosion via CD39adenosine signal pathway in autoimmune arthritis. EBioMedicine. (2019) 43:620-31. doi: 10.1016/j.ebiom.2019.04.058

4. Herrmann M, Farrell CL, Pusceddu I, Fabregat-Cabello N, Cavalier E. Assessment of vitamin D status-a changing landscape. Clin Chem Lab Med. (2017) 55:3-26. doi: 10.1515/cclm-2016-0264

5. Enko D, Kriegshäuser G, Stolba R, Worf E, Halwachs-Baumann G. Method evaluation study of a new generation of vitamin D assays. Biochem Med. (2015) 25:203-12. doi: 10.11613/BM.2015.020

6. Wang H, Chen W, Li D, Yin X, Zhang X, Olsen N, et al. Vitamin D and Chronic Diseases. Aging Dis. (2017) 8:346-53. doi: 10.14336/AD.2016.1021 studies support an association between vitamin D and AITD, where vitamin D deficiency increases the risk of AITD. At present, some literatures have reported that vitamin D treatment can improve the condition of patients with AITD, but whether it can prevent AITD has not been studied. In addition, because vitamin $\mathrm{D}$ levels in the body are affected by many factors, results reported by various studies are inconsistent. Whether vitamin D supplementation can help prevent and/or treat thyroid disease, deserves a clinical trial in multiple centers in the future. Recently, researchers have proposed that the skeletal health is maintained at vitamin $\mathrm{D}$ level of $30-40 \mathrm{ng} / \mathrm{mL}$, but higher vitamin $\mathrm{D}$ levels does not exert better effects. Vitamin D levels higher than $40 \mathrm{ng} / \mathrm{mL}$ tend to loose their beneficial effects on bone. If supplementing vitamin D is considered to be useful for AITD patients, it is important to address the following questions: how to supplement vitamin $\mathrm{D}$, and monitor vitamin $\mathrm{D}$ level and thyroid function, and at what level can vitamin D improve the condition of patients with AITD? Therefore, these questions are worth exploring.

\section{AUTHOR CONTRIBUTIONS}

WC: conceptualization and supervision. WZ: validation, visualization, and project administration. HW: formal analysis. CM, YZ, and RX: investigation. RZ: data curation and writingoriginal draft preparation. SZ: writing-review and editing. All authors contributed to the article and approved the submitted version.

\section{FUNDING}

This work was supported by Yunnan Fundamental Research Projects [Grant No. 2018FE001(-100)]. It was further supported by a grant from the scientific research fund project of the Yunnan provincial department of education [Grant No. 2017zDX183].
7. Muscogiuri G, Mitri J, Mathieu C, Badenhoop K, Tamer G, Orio F, et al. Mechanisms in endocrinology: vitamin $\mathrm{D}$ as a potential contributor in endocrine health and disease. Eur J Endocrinol. (2014) 171:R10110. doi: 10.1530/EJE-14-0158

8. Bouchemal M, Hakem D, Azzouz M, Touil-Boukoffa C, Mezioug D. Vitamin D levels correlate with metabolic syndrome criteria in algerian patients: the ex-vivo immunomodulatory effect of $\alpha, 25$ Dihydroxyvitamin D3. Endocr Metab Immune Disord Drug Targets. (2020) 20:1282-94. doi: 10.2174/1871530320666200402121917

9. Djeraba Z, Benlabidi F, Djaballah-Ider FZ, Medjeber O, ArroulLammali A, et al. Vitamin D status in Algerian Behçet's disease patients: an immunomodulatory effect on $\mathrm{NO}$ pathway. Immunopharmacol Immunotoxicol. (2017) 39:243-50. doi: 10.1080/08923973.2017.1327967

10. Bellan M, Andreoli L, Mele C, Sainaghi PP, Rigamonti C, Piantoni S, et al. Pathophysiological role and therapeutic implications of vitamin D in autoimmunity: focus on chronic autoimmune diseases. Nutrients. (2020) 12:789. doi: 10.3390/nu12030789

11. Zhou L, Wang J, Li J, Li T, Chen Y, June RR, et al. 1,25-Dihydroxyvitamin D3 ameliorates collagen-induced arthritis via suppression of Th17 cells through miR-124 mediated inhibition of IL-6 signaling. Front Immunol. (2019) 10:178. doi: 10.3389/fimmu.2019.00178 
12. Ragusa F, Fallahi P, Elia G, Gonnella D, Paparo SR, Giusti C, et al. Hashimotos' thyroiditis: epidemiology, pathogenesis, clinic and therapy. Best Pract Res Clin Endocrinol Metab. (2019) 33:101367. doi: 10.1016/j.beem.2019.101367

13. Skrobot A, Demkow U, Wachowska M. Immunomodulatory role of vitamin D: a review. Adv Exp Med Biol. (2018) 1108:1323. doi: 10.1007/5584_2018_246

14. Altieri B, Muscogiuri G, Barrea L, Mathieu C, Vallone CV, Mascitelli $\mathrm{L}$, et al. Does vitamin D play a role in autoimmune endocrine disorders? A proof of concept. Rev Endocr Metab Disord. (2017) 18:33546. doi: 10.1007/s11154-016-9405-9

15. Hossein-nezhad A, Holick MF. Vitamin D for health: a global perspective. Mayo Clin Proc. (2013) 88:720-55. doi: 10.1016/j.mayocp.2013.05.011

16. Lang PO, Aspinall R. Can we translate vitamin D immunomodulating effect on innate and adaptive immunity to vaccine response. Nutrients. (2015) 7:2044-60. doi: 10.3390/nu7032044

17. Luo Y, Zheng SG. Hall of Fame among pro-inflammatory cytokines: interleukin-6 gene and its transcriptional regulation mechanisms. Front Immunol. (2016) 7:604. doi: 10.3389/fimmu.2016.00604

18. Sandal I, Karydis A, Luo J, Prislovsky A, Whittington KB, Rosloniec EF, et al. Bone loss and aggravated autoimmune arthritis in HLA-DR $\beta 1$-bearing humanized mice following oral challenge with Porphyromonas gingivalis. Arthritis Res Ther. (2016) 18:249. doi: 10.1186/s13075-016-1143-6

19. Sadeghi K, Wessner B, Laggner U, Ploder M, Tamandl D, Friedl J, et al. Vitamin D3 down-regulates monocyte TLR expression and triggers hyporesponsiveness to pathogen-associated molecular patterns. Eur $J$ Immunol. (2006) 36:361-70. doi: 10.1002/eji.200425995

20. Yang S, Xie C, Chen Y, Wang J, Chen X, Lu Z, et al. Differential roles of TNF $\alpha$-TNFR1 and TNF $\alpha$-TNFR2 in the differentiation and function of CD4+Foxp3+ induced Treg cells in vitro and in vivo periphery in autoimmune diseases. Cell Death Dis. (2019) 10:27. doi: 10.1038/s41419-018-1266-6

21. Yang S, Wang J, Brand DD, Zheng SG. Role of TNF-TNF receptor 2 signal in regulatory T Cells and its therapeutic implications. Front Immunol. (2018) 9:784. doi: 10.3389/fimmu.2018.00784

22. Li N, Wang JC, Liang TH, Zhu MH, Wang JY, Fu XL, et al. Pathologic finding of increased expression of interleukin-17 in the synovial tissue of rheumatoid arthritis patients. Int J Clin Exp Pathol. (2013) 6:1375-9.

23. Jacob N, Yang H, Pricop L, Liu Y, Gao X, Zheng SG, et al. Accelerated pathological and clinical nephritis in systemic lupus erythematosus-prone New Zealand Mixed 2328 mice doubly deficient in TNF receptor 1 and TNF receptor 2 via a Th17-associated pathway. J Immunol. (2009) 182:253241. doi: 10.4049/jimmunol.0802948

24. Santinon F, Batignes M, Mebrek ML, Biton J, Clavel G, Hervé R, et al. Involvement of tumor necrosis factor receptor type II in FoxP3 stability and as a marker of Treg cells specifically expanded by anti-tumor necrosis factor treatments in rheumatoid arthritis. Arthritis Rheumatol. (2020) 72:57687. doi: $10.1002 /$ art.41134

25. Zheng SG, Meng L, Wang JH, Watanabe M, Barr ML, Cramer DV, et al. Transfer of regulatory $\mathrm{T}$ cells generated ex vivo modifies graft rejection through induction of tolerogenic $\mathrm{CD} 4+\mathrm{CD} 25+$ cells in the recipient. Int Immunol. (2006) 18:279-89. doi: 10.1093/intimm/dxh368

26. Fan H, Wang J, Zhou X, Liu Z, Zheng SG. Induction of antigen-specific immune tolerance by TGF-beta-induced CD4+Foxp3+ regulatory T cells. Int J Clin Exp Med. (2009) 2:212-20.

27. Ramalingam R, Larmonier $\mathrm{CB}$, Thurston $\mathrm{RD}$, Midura-Kiela MT, Zheng SG, Ghishan FK, et al. Dendritic cell-specific disruption of TGF- $\beta$ receptor II leads to altered regulatory $\mathrm{T}$ cell phenotype and spontaneous multiorgan autoimmunity. J Immunol. (2012) 189:3878-93. doi: 10.4049/jimmunol.1201029

28. Kundu R, Theodoraki A, Haas CT, Zhang Y, Chain B, Kriston-Vizi J, et al. Cell-type-specific modulation of innate immune signalling by vitamin D in human mononuclear phagocytes. Immunology. (2017) 150:5563. doi: 10.1111/imm.12669

29. Kong N, Lan Q, Chen M, Wang J, Shi W, Horwitz DA, et al. Antigenspecific transforming growth factor $\beta$-induced Treg cells, but not natural Treg cells, ameliorate autoimmune arthritis in mice by shifting the Th17/Treg cell balance from Th17 predominance to Treg cell predominance. Arthritis Rheum. (2012) 64:2548-58. doi: 10.1002/art.34513
30. Chen W, Wang J, Xu Z, Huang F, Qian W, Ma J, et al. Apremilast ameliorates experimental arthritis via suppression of th 1 and th 17 cells and enhancement of cd4+foxp3+ regulatory t cells differentiation. Front Immunol. (2018) 9:1662. doi: 10.3389/fimmu.2018.01662

31. Lu L, Wang J, Zhang F, Chai Y, Brand D, Wang X, et al. Role of SMAD and non-SMAD signals in the development of Th17 and regulatory $\mathrm{T}$ cells. J Immunol. (2010) 184:4295-306. doi: 10.4049/jimmunol.0903418

32. Lan Q, Zhou X, Fan H, Chen M, Wang J, Ryffel B, et al. Polyclonal CD4+Foxp3+ Treg cells induce TGF $\beta$-dependent tolerogenic dendritic cells that suppress the murine lupus-like syndrome. J Mol Cell Biol. (2012) 4:40919. doi: $10.1093 / \mathrm{jmcb} / \mathrm{mjs} 040$

33. Vanherwegen AS, Gysemans C, Mathieu C. Vitamin D endocrinology on the cross-road between immunity and metabolism. Mol Cell Endocrinol. (2017) 453:52-67. doi: 10.1016/j.mce.2017.04.018

34. Bizzaro G, Shoenfeld Y. Vitamin D and thyroid autoimmune diseases: the known and the obscure. Immunol Res. 61:2015:1079. doi: $10.1007 / \mathrm{s} 12026-014-8591-3$

35. Weaver CT, Harrington LE, Mangan PR, Gavrieli M, Murphy KM. Th17: an effector CD4 T cell lineage with regulatory T cell ties. Immunity. (2006) 24:677-88. doi: 10.1016/j.immuni.2006.06.002

36. Gao Y, Tang J, Chen W, Li Q, Nie J, Lin F, et al. Inflammation negatively regulates FOXP3 and regulatory T-cell function via DBC1. Proc Natl Acad Sci USA. (2015). 112:E3246-54. doi: 10.1073/pnas.1421463112

37. Luo Y, Xue Y, Wang J, Dang J, Fang Q, Huang G, et al. Negligible effect of sodium chloride on the development and function of TGF$\beta$-induced CD4+ Foxp3+ regulatory T cells. Cell Rep. (2019) 26:186979.e3. doi: 10.1016/j.celrep.2019.01.066

38. Chen M, Lin X, Liu Y, Li Q, Deng Y, Liu Z, et al. The function of BAFF on $\mathrm{T}$ helper cells in autoimmunity. Cytokine Growth Factor Rev. (2014) 25:301-5. doi: 10.1016/j.cytogfr.2013.12.011

39. Dankers W, Davelaar N, van Hamburg JP, van de Peppel J, Colin EM, Lubberts E. Human memory Th17 cell populations change into Anti-inflammatory cells with regulatory capacity upon exposure to active vitamin D. Front Immunol. (2019) 10:1504. doi: 10.3389/fimmu.2019.01504

40. Horwitz DA, Zheng SG, Gray JD. Natural and TGF-beta-induced Foxp3(+)CD4(+) CD25(+) regulatory $\mathrm{T}$ cells are not mirror images of each other. Trends Immunol. (2008) 29:429-35. doi: 10.1016/j.it.2008.06.005

41. Liu Y, Lan Q, Lu L, Chen M, Xia Z, Ma J, et al. Phenotypic and functional characteristic of a newly identified CD8+ Foxp3- CD103+ regulatory T cells. J Mol Cell Biol. (2014) 6:81-92. doi: 10.1093/jmcb/mjt026

42. Xu A, Liu Y, Chen W, Wang J, Xue Y, Huang F, et al. TGF- $\beta$-Induced regulatory $\mathrm{T}$ cells directly suppress $\mathrm{B}$ cell responses through a noncytotoxic mechanism. J Immunol. (2016) 196:3631-41. doi: 10.4049/jimmunol.1501740

43. Fisher SA, Rahimzadeh M, Brierley C, Gration B, Doree C, Kimber CE, et al. The role of vitamin $\mathrm{D}$ in increasing circulating $\mathrm{T}$ regulatory cell numbers and modulating $\mathrm{T}$ regulatory cell phenotypes in patients with inflammatory disease or in healthy volunteers: A systematic review. PLoS ONE. (2019) 14:e0222313. doi: 10.1371/journal.pone.0222313

44. Li C, Yuan J, Zhu YF, Yang XJ, Wang Q, Xu J, et al. Imbalance of Th17/Treg in different subtypes of autoimmune thyroid diseases. Cell Physiol Biochem. (2016) 40:245-52. doi: 10.1159/000452541

45. Bishop E, Ismailova A, Dimeloe SK, Hewison M, White JH. Vitamin D and immune regulation: antibacterial, antiviral, anti-inflammatory. JBMR Plus. (2020) 5. doi: $10.1002 / \mathrm{jbm} 4.10405$

46. Liao T, Xue Y, Zhao D, Li S, Liu M, Chen J, et al. In Vivo attenuation of antibody-mediated acute renal allograft rejection by ex vivo TGF- $\beta$ induced CD4+Foxp3+ regulatory T cells. Front Immunol. (2017) 8:1334. 16. doi: 10.3389/fimmu.2017.01334

47. Xiao ZX, Zheng X, Hu L, Wang J, Olsen N, Zheng SG. Immunosuppressive effect of B7-H4 pathway in a murine systemic lupus erythematosus model. Front Immunol. (2017) 8:1765. doi: 10.3389/fimmu.2017.01765

48. Krysiak R, Szkróbka W, Okopień B. The effect of vitamin D on thyroid autoimmunity in levothyroxine-treated women with hashimoto's thyroiditis and normal vitamin D status. Exp Clin Endocrinol Diabetes. (2017) 125:22933. doi: 10.1055/s-0042-123038

49. Chahardoli R, Saboor-Yaraghi AA, Amouzegar A, Khalili D, Vakili AZ, Azizi F. Can supplementation with vitamin D modify thyroid autoantibodies (AntiTPO Ab, Anti-Tg Ab) and thyroid profile (T3, T4, TSH) in Hashimoto's 
Thyroiditis? a double blind, randomized clinical trial. Horm Metab Res. (2019) 51:296-301. doi: 10.1055/a-0856-1044

50. Kim D. The role of vitamin D in thyroid diseases. Int J Mol Sci. (2017) 18:1949. doi: 10.3390/ijms18091949

51. Tamer G, Arik S, Tamer I, Coksert D. Relative vitamin D insufficiency in Hashimoto's thyroiditis. Thyroid. (2011) 21:891-6. doi: 10.1089/thy.2009.0200

52. Ma J, Wu D, Li C, Fan C, Chao N, Liu J, et al. Lower serum 25-hydroxyvitamin $\mathrm{D}$ level is associated with 3 types of autoimmune thyroid diseases. Medicine (Baltimore). (2015) 94:e1639. doi: 10.1097/MD.0000000000001639

53. Bozkurt NC, Karbek B, Ucan B, Sahin M, Cakal E, Ozbek M, et al. The association between severity of vitamin D deficiency and Hashimoto's thyroiditis. Endocr Pract. (2013) 19:479-84. doi: 10.4158/EP12376.OR

54. Mazokopakis EE, Papadomanolaki MG, Tsekouras KC, Evangelopoulos AD, Kotsiris DA, Tzortzinis AA. Is vitamin D related to pathogenesis and treatment of Hashimoto's thyroiditis. Hell J Nucl Med. (2015) 18:222-7.

55. Murdaca G, Tonacci A, Negrini S, Greco M, Borro M, Puppo F, et al. Emerging role of vitamin D in autoimmune diseases: an update on evidence and therapeutic implications. Autoimmun Rev. (2019) 18:102350. doi: 10.1016/j.autrev.2019.102350

56. Chao G, Zhu Y, Fang L. Correlation between Hashimoto's thyroiditisrelated thyroid hormone levels and 25-hydroxyvitamin D. Front Endocrinol. (2020) 11:4. doi: 10.3389/fendo.2020.00004

57. Botelho IMB, Moura Neto A, Silva CA, Tambascia MA, Alegre SM, ZantutWittmann DE. Vitamin D in Hashimoto's thyroiditis and its relationship with thyroid function and inflammatory status. Endocrine J. (2018) 65:102937. doi: 10.1507/endocrj.EJ18-0166

58. Nodehi M, Ajami A, Izad M, Asgarian Omran H, Chahardoli R, Amouzegar A, et al. Effects of vitamin D supplements on frequency of CD4(+) T-cell subsets in women with Hashimoto's thyroiditis: a double-blind placebo-controlled study. Eur J Clin Nutr. (2019) 73:1236-43. doi: 10.1038/s41430-019-0395-z

59. Vahabi Anaraki P, Aminorroaya A, Amini M, Momeni F, Feizi A, Iraj B, et al. Effect of Vitamin D deficiency treatment on thyroid function and autoimmunity markers in Hashimoto's thyroiditis: a doubleblind randomized placebo-controlled clinical trial. J Res Med Sci. (2017) 22:103. doi: 10.4103/jrms.JRMS_1048_16

60. Zhang Q, Wang Z, Sun M, Cao M, Zhu Z, Fu Q, et al. Association of high vitamin $\mathrm{D}$ status with low circulating thyroid-stimulating hormone independent of thyroid hormone levels in middle-aged and elderly males. Int J Endocrinol. (2014) 2014:631819. doi: 10.1155/2014/631819
61. D’Aurizio F, Villalta D, Metus P, Doretto P, Tozzoli R. Is vitamin $\mathrm{D}$ a player or not in the pathophysiology of autoimmune thyroid diseases? Autoimmunity Rev. (2015) 14:363-9. doi: 10.1016/j.autrev.2014. 10.008

62. Yasmeh J, Farpour F, Rizzo V, Kheradnam S, Sachmechi I. Hashimoto thyroiditis not associated with vitamin D deficiency. Endocr Pract. (2016) 22:809-13. doi: 10.4158/EP15934.OR

63. Phenekos C, Vryonidou A, Gritzapis AD, Baxevanis CN, Goula M, Papamichail M. Th1 and Th2 serum cytokine profiles characterize patients with Hashimoto's thyroiditis (Th1) and Graves' disease (Th2). Neuroimmunomodulation. (2004) 11:209-13. doi: 10.1159/000078438

64. Nettore IC, Albano L, Ungaro P, Colao A, Macchia PE. Sunshine vitamin and thyroid. Rev Endocr Metab Disord. (2017) 18:347-54. doi: 10.1007/s11154-017-9406-3

65. Zhang H, Liang L, Xie Z. Low vitamin D status is associated with increased thyrotropin-receptor antibody titer in Graves disease. Endocr Pract. (2015) 21:258-63. doi: 10.4158/EP14191.OR

66. Ahn HY, Chung YJ, Cho BY. Serum 25-hydroxyvitamin D might be an independent prognostic factor for Graves disease recurrence. Medicine. (2017) 96:e7700. doi: 10.1097/MD.0000000000007700

67. Ke W, Sun T, Zhang Y, He L, Wu Q, et al. 25-Hydroxyvitamin D serum level in Hashimoto's thyroiditis, but not Graves' disease is relatively deficient. Endocrine J. (2017) 64:581-7. doi: 10.1507/endocrj.EJ1 6-0547

68. Cho YY, Chung YJ. Vitamin D supplementation does not prevent the recurrence of Graves' disease. Sci Rep. (2020) 10:9. doi: 10.1038/s41598-019-55107-9

Conflict of Interest: The authors declare that the research was conducted in the absence of any commercial or financial relationships that could be construed as a potential conflict of interest.

Copyright (c) 2021 Zhao, Zhang, Ma, Zhao, Xiong, Wang, Chen and Zheng. This is an open-access article distributed under the terms of the Creative Commons Attribution License (CC BY). The use, distribution or reproduction in other forums is permitted, provided the original author(s) and the copyright owner(s) are credited and that the original publication in this journal is cited, in accordance with accepted academic practice. No use, distribution or reproduction is permitted which does not comply with these terms. 